\title{
The effect of urban cover fraction on the retrieval of space-borne surface soil moisture at L-band
}

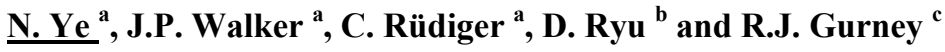 \\ ${ }^{a}$ Department of Civil Engineering, Monash University, Australia \\ ${ }^{b}$ Department of Infrastructure Engineering, University of Melbourne, Australia \\ ${ }^{c}$ NERC Environmental Systems Science Centre, University of Reading, United Kingdom \\ Email:ye.nan@monash.edu
}

\begin{abstract}
The world's first satellite dedicated to soil moisture measurement was launched by the European Space Agency on 2nd November 2009. One objective of this Soil Moisture and Ocean Salinity (SMOS) mission is to obtain global near-surface (top $\sim 5 \mathrm{~cm}$ ) soil moisture every 2 to 3 days with a target accuracy of $0.04 \mathrm{~m}^{3} / \mathrm{m}^{3}$. To achieve this goal, the Microwave Imaging Radiometer with Aperture Synthesis (MIRAS) mounted on SMOS is used to observe the microwave emission from the Earth's surface at L-band $(\sim 1.4 \mathrm{GHz})$ with a spatial resolution of $\sim 45 \mathrm{~km}$. The soil moisture and vegetation water content are then retrieved simultaneously from fully-polarized brightness temperature observations at multiple incidence angles. However, given the coarse scale of the SMOS pixels, existence of non-soil targets (such as urban area, standing water, and surface rock) contributes to the overall microwave emission, potentially reducing the accuracy of the retrieved soil moisture.
\end{abstract}

The impact of such confounding factors has not been thoroughly assessed in the context of soil moisture retrieval algorithms, since their microwave behaviours have not been well understood and/or modelled. Ignoring their contribution or simply assuming they behave like vegetated soil targets may result in an increased retrieval error. Therefore, microwave contribution of urban areas has been considered as a brightness temperature uncertainty for current generation soil moisture retrieval models that do not account for their presence. Consequently, this study has investigated the relationship between urban induced brightness temperature uncertainties and urban fraction under warm dry soil conditions, and then used this relationship to identify SMOS pixels expected to have non-negligible impacts from urban areas.

An airborne dataset: the NAFE'06 (National Airborne Field Experiment 2006), and two urban extension datasets: the LUNSW (Land use: New South Wales) and the MODIS 500-m (MODIS Urban Land Cover $500-\mathrm{m}$ ) were used to make this assessment. The NAFE'06 was a large scale field campaign undertaken over the Murrumbidgee catchment, in southeast of Australia, in spring of 2006. A mean surface (top $5 \mathrm{~cm}$ ) soil moisture of $0.07 \mathrm{~m}^{3} / \mathrm{m}^{3}$ and a mean surface $(2.5 \mathrm{~cm})$ soil temperature of $21{ }^{\circ} \mathrm{C}$ was observed during the campaign. The brightness temperature observations over the city of Wagga Wagga and surrounding natural land surfaces within the Kyeamba study area from NAFE'06 were used to establish the urban induced brightness temperature uncertainties and urban fraction. The LUNSW dataset was used to distinguish urban areas and calculate urban fraction. As expected, under dry soil conditions, urban induced brightness temperature uncertainties increased with urban fraction. To assess whether urban induced brightness temperature can be ignored, the target SMOS brightness temperature error of $4 \mathrm{~K}$ was used as a benchmark by which to set an urban fraction threshold for constraining the brightness temperature uncertainty.

A urban fraction threshold of 9 - 16\% was obtained, and subsequently applied to the MODIS 500-m urban fraction map in order to identify SMOS pixels across Australia that are expected to have non-negligible urban induced brightness temperature uncertainties. The critical assumption of this method is that the microwave behaviour of the studied city is similar to that of all cities in Australia. This study suggests that approximately $0.2 \%$ (116 out of 43,323) SMOS pixels over Australia are likely to have non-negligible brightness temperature uncertainties due to urban areas under warm dry conditions.

Keywords: passive microwave, soil moisture, remote sensing, urban fraction 


\section{INTRODUCTION}

Soil moisture plays a key role in the water, energy, and carbon cycles, since it controls the interaction at the interface between the atmosphere and the land surface (Dirmeyer, 2000; Koster and Suarez, 2001). Due to its variability in space and time, surface soil moisture is difficult to be measured at appropriate spatial and temporal resolution over regional and/or global scales using traditional ground based techniques. However, remote sensing provides a potential solution to this important problem, with the Soil Moisture and Ocean Salinity (SMOS; Kerr, et al., 2010 a) satellite launched by the European Space Agency (ESA) on $2^{\text {nd }}$ Nov. 2009. This is the first soil moisture dedicated space mission providing surface (top $\sim 5 \mathrm{~cm}$ ) soil moisture every 2 to 3 days with a spatial resolution of $\sim 45 \mathrm{~km}$. The target accuracy is $0.04 \mathrm{~m}^{3} / \mathrm{m}^{3}$ when converting observed microwave emission from the Earth's surface at L-band $(\sim 1.4 \mathrm{GHz})$ into soil moisture. However, given the coarse scale of the SMOS pixels, the existence of urban areas contributes to the overall microwave emission due to its non-soil emission. This mixed pixel response may potentially reduce the accuracy of the retrieved soil moisture significantly. The impact of such confounding factors has not been thoroughly assessed in the context of soil moisture retrieval algorithms, since their microwave behaviours have not been well understood and/or modelled.

According to Schneider et al. (2009), urban areas occupy less than $0.5 \%$ of the world's land area, implying that urban areas are either not present or are an insignificant contribution in most SMOS pixels, and hence their effect can be ignored. However, urbanisation is not evenly smeared across the globe, with many SMOS sized areas having considerable urbanisation, and hence it is important to know the level of urbanisation fraction that can be tolerated. Such an urban fraction threshold can therefore be used to distinguish SMOS pixels where the contribution of urban areas to the brightness temperature observations results in intolerable errors, meaning that those pixels need to be flagged or a brightness temperature correction imposed. To date there are only a few synthetic studies (Kerr, et al., 2010 b; Loew, 2008) that have focused on the effect of urban areas on the soil moisture retrieval, and none of these studies have been performed using real microwave observations. In the SMOS ATBD (Kerr, et al., $2010 \mathrm{~b}$ ), the microwave behaviour of urban areas is suggested to be similar to that of rock or very dry bare soil, and an urban fraction threshold of $11 \%$ for SMOS target accuracy of $0.04 \mathrm{~m}^{3} / \mathrm{m}^{3}$ was proposed. In a different study, Loew (2008) determined a $15-20 \%$ urban fraction threshold from model simulations over the Upper Danube catchment in southern Germany. Consequently, these urban fraction thresholds must be more fully explored with experimental data.

\section{METHODOLOGY}

Urban brightness temperature contributions are not taken into account in current soil moisture retrieval models, potentially contributing additional soil moisture retrieval error, and thus making the overall soil moisture retrieval accuracy lower than the SMOS target accuracy of $0.04 \mathrm{~m}^{3} / \mathrm{m}^{3}$. Therefore urban contributions to brightness temperature uncertainties are examined in this study. The urban induced brightness temperature uncertainty $\left(\triangle T B_{\text {urban }}\right)$ is defined as the brightness temperature difference between non-urban components in the scene $\left(T B_{\text {non-urban }}\right)$ and that of the entire scene $\left(T B_{\text {all }}\right)$. The target maximum value of SMOS equivalent random brightness temperature error of $4 \mathrm{~K}$ (Kerr and Waldteufel, 2003) is used to determine an urban fraction threshold, and subsequently classify Australian SMOS pixels potentially having a non-negligible urban effect. The urban fraction for $4 \mathrm{~K}$ brightness temperature uncertainty over Australian land surfaces is determined using airborne passive microwave observations at L-band over a medium-sized Australian city from the National Airborne Field Experiment 2006 (NAFE’06) dataset (Merlin, et al., 2008). The urban fraction was estimated using the Land Use: New South Wales (LUNSW; New South Wales Department of Environment \& Climate Change, 2007) coverage. The urban fraction threshold was then applied across Australia to assess the potential urban effect on SMOS pixels, using the urban fraction calculated from the MODIS Urban Land Cover 500-m (MODIS 500-m; Schneider et al., 2009) coverage, since the extension of LUNSW is limited to New South Wales. SMOS pixels were generated by re-sampling the SMOS DGG (Discrete Global Grid) grid using the Voronoi diagram technique (Lomas, 2003). One of nine re-sampled replicated SMOS DGG grids is shown in Figure 1.This method is based on an assumption that all Australian cities have similar material composition, and that the studied city may be used as a proxy to estimate the microwave behaviour of other cities, such that the urban fraction threshold obtained from this city is suitable for all cities across Australia.

\section{STUDY AREA AND DATASETS}

Data from an Australian airborne field campaign, the National Airborne Field Experiment 2006 (NAFE'06; Merlin, et al., 2008), were used in this study together with an Australian land use classification dataset LUNSW (Land Use: New South Wales; New South Wales Department of Environment \& Climate Change, 
2007), and a global urban extension dataset MODIS 500-m (MODIS Urban Land Cover 500-m; Schneider et al., 2009) that were used to identify the urban areas. The Kyeamba study area in NAFE'06, re-sampled SMOS DGG pixels, and urban areas based on LUNSW and MODIS 500-m are plotted in Figure 1.

To assess urban induced brightness temperature uncertainties over the entire Australian land mass, the urban extension dataset was required to have four features: 1) large scale coverage; 2) high spatial resolution; 3) high accuracy in size and location; and 4) classified urban areas having distinctive radiometric characteristics from natural targets. For the purpose of being comparable globally, an existing global urban extension datasets was selected in this study.

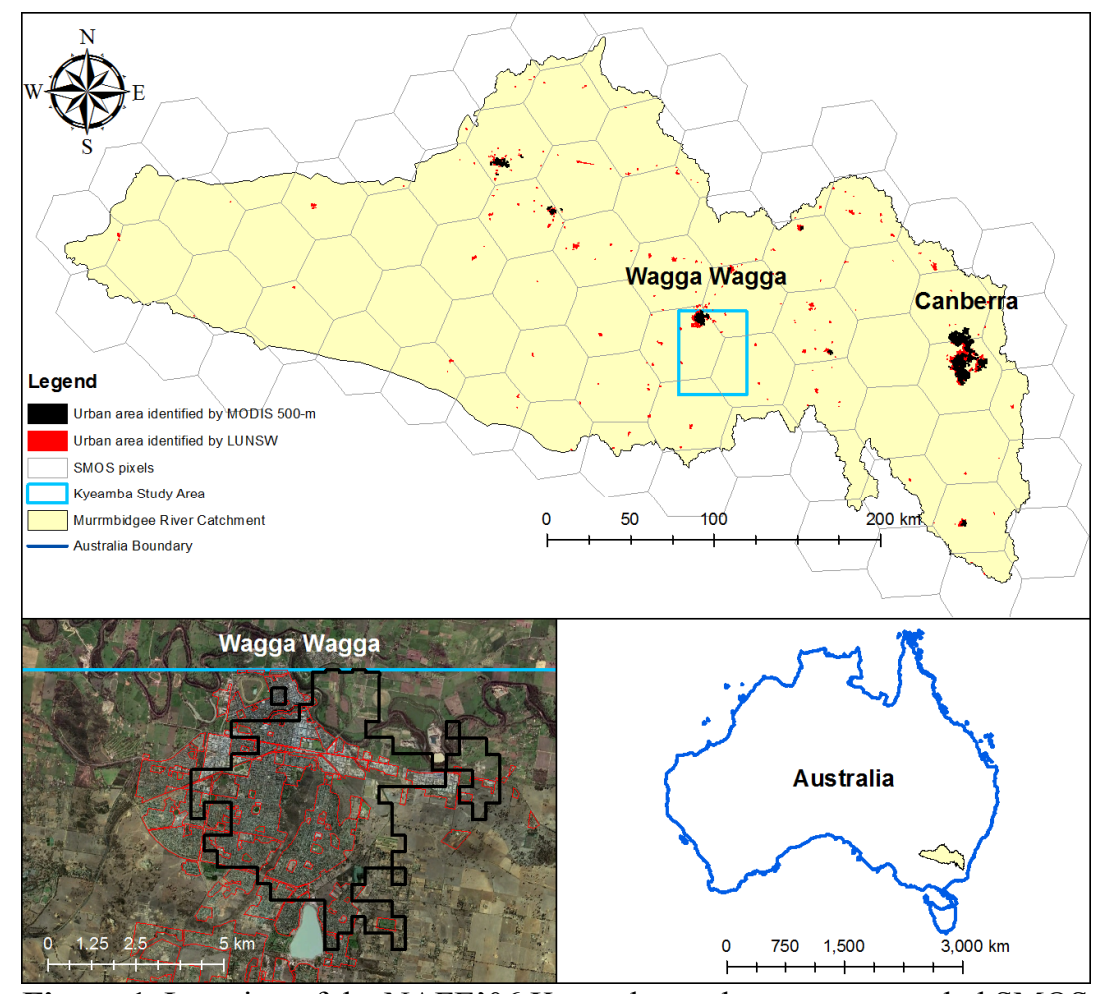

Figure 1. Location of the NAFE'06 Kyeamba study area, re-sampled SMOS DGG pixels, and urban area identified based on MODIS 500-m and

LUNSW in the Murrumbidgee River Catchment. The insets show i) the urban area boundary for the city of Wagga Wagga from the two urban masks and ii) location of the Murrumbidgee River Catchment in Australia.

There are currently ten global urban maps available, as listed in Table 1. Amongst them, Map 4 was discarded due to its coarse resolution, and Maps 1, 9 and 10 were not taken into consideration since the definitions of urban areas are relative to population and/or income levels. The urban size accuracies of the remaining maps were assessed in Schneider et al. (2010) by comparing them with 30-m Landsat-based land surface maps. According to the assessment result, the MODIS Urban Land Cover 500-m (MODIS 500-m; Schneider et al., 2009) has the highest accuracy at pixel level and urban size, so that it was chosen as the basis to calculate the urban fraction of the SMOS pixels in this study. However, the inset in the left bottom of

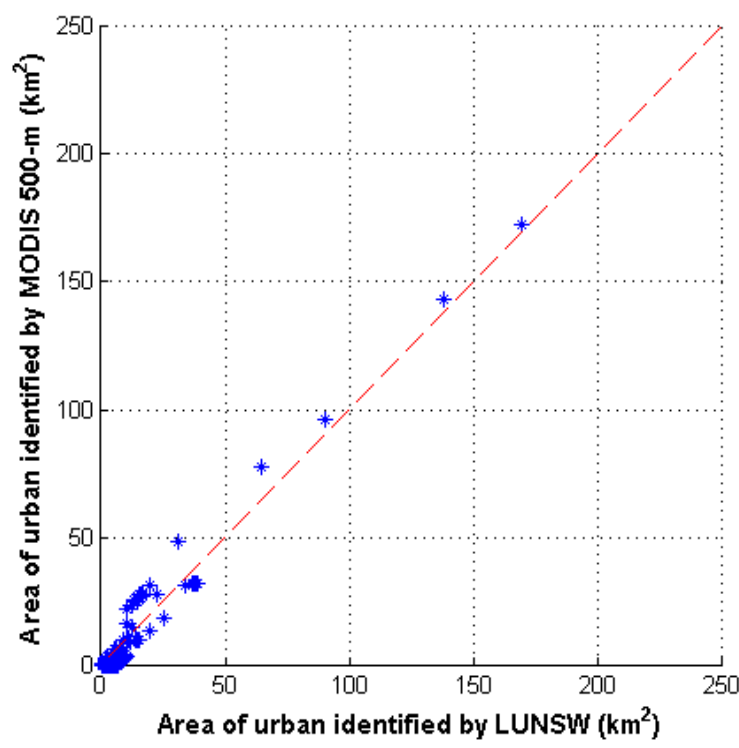

Figure 2. Comparison of urban areas derived respectively from LUNSW and MODIS 500-m at SMOS scale.
Figure 1 suggests that MODIS 500-m may have a displacement of $\sim 1 \mathrm{~km}$ to the location of Wagga Wagga, while the LUNSW-based map has a high positional accuracy compared with the Google Earth image. As this displacement is a considerable bias for high resolution $(\sim 1 \mathrm{~km})$ airborne brightness temperature observations, the LUNSW-based map was selected for use with the airborne data in this study, and MODIS 500-m was only used for estimating Australia-wide urban fraction of SMOS pixels since the extension of LUNSW is limited to New South Wales.

Before applying the urban fraction threshold based on MODIS 500-m, it is important to understand the potential impact on spatial resolution estimates using the LUNSW-based and MODIS 500-m maps at the SMOS scale. Hence the total urban areas of SMOS pixels across the Murrumbidgee River Catchment were calculated using both sources and compared in Figure 2. The comparison shows a good agreement with a correlation coefficient of 0.977 , and a Root- 
Ye et al., The effect of urban cover fraction on the retrieval of surface soil moisture at L-band

Table 1. Main characteristics of ten global urban maps (adapted from Schneider et al 2009; 2010).

\begin{tabular}{|c|c|c|c|c|c|c|}
\hline ID & Abbreviation & Map (citation) & $\begin{array}{c}\text { Factor of } \\
\text { defining urban } \\
\text { or urban-related } \\
\text { feature }\end{array}$ & Resolution & Main source data & $\begin{array}{c}\text { Accuracy } \\
\text { at pixel } \\
\text { level } \\
(\text { urban } \\
\text { size } \mathbf{R}^{2} \text { ) }\end{array}$ \\
\hline 1 & $\begin{array}{c}\text { VMAP } \\
\text { (Danko, 1992) }\end{array}$ & $\begin{array}{l}\text { Vector Map Level } \\
\text { Zero }\end{array}$ & Population & $1: 1$ million & Aeronautical charts, maps & - \\
\hline 2 & $\begin{array}{l}\text { GLC2000 } \\
\text { (Bartholome and } \\
\text { Belward, 2005) }\end{array}$ & $\begin{array}{l}\text { Global Land Cover } \\
2000\end{array}$ & $\begin{array}{l}\text { Artificial surfaces } \\
\text { and associated } \\
\text { areas }\end{array}$ & $\sim 1 \mathrm{~km}$ & $\begin{array}{c}\text { SPOT-Vegetation, Nighttime } \\
\text { lights data }\end{array}$ & $\begin{array}{l}\sim 90 \% \\
(0.90)\end{array}$ \\
\hline 3 & $\begin{array}{l}\text { GlobCover } \\
\text { (Arino et al., 2007; } \\
\text { ESA, 2008) }\end{array}$ & GlobCover v2.2 & $\begin{array}{l}\text { Artificial surfaces } \\
\text { and associated } \\
\text { areas }\end{array}$ & $\sim 300 \mathrm{~m}$ & MERIS & $\begin{array}{l}\sim 90 \% \\
(0.30)\end{array}$ \\
\hline 4 & $\begin{array}{c}\text { HYDE } \\
\text { (Goldewijk, 2001, } \\
\text { 2005) }\end{array}$ & $\begin{array}{c}\text { History Database of } \\
\text { the Global } \\
\text { Environment v3 }\end{array}$ & $\begin{array}{l}\text { Urban and built- } \\
\text { up areas }\end{array}$ & $\sim 10 \mathrm{~km}$ & $\begin{array}{l}\text { Landscan, UN census data, } \\
\text { city gazetteers }\end{array}$ & - \\
\hline 5 & $\begin{array}{l}\text { IMPSA } \\
\text { (Elvidge et al., } \\
\text { 2007) }\end{array}$ & $\begin{array}{l}\text { Global Impervious } \\
\text { Surface Area }\end{array}$ & $\begin{array}{l}\text { Impervious } \\
\text { surface area }\end{array}$ & $\sim 1 \mathrm{~km}$ & $\begin{array}{l}\text { Landscan, Nighttime lights } \\
\text { data Landset data for training }\end{array}$ & $\begin{array}{l}\sim 90 \% \\
(0.60)\end{array}$ \\
\hline 6 & $\begin{array}{l}\text { MODIS } 500 \mathrm{~m} \\
\text { (Schneider et al., } \\
\text { 2009) }\end{array}$ & $\begin{array}{l}\text { MODIS Urban Land } \\
\text { Cover } 500 \mathrm{~m}\end{array}$ & $\begin{array}{l}\text { Urban and built- } \\
\text { up areas }\end{array}$ & $\sim 500 \mathrm{~m}$ & $\begin{array}{l}\text { MODIS and Landsat-based } \\
\text { map for training and } \\
\text { assessment. }\end{array}$ & $\begin{array}{c}93 \% \\
(0.90)\end{array}$ \\
\hline 7 & $\begin{array}{c}\text { MODIS } 1 \mathrm{~km} \\
\text { (Schneider et al., } \\
\text { 2003) }\end{array}$ & $\begin{array}{l}\text { MODIS Urban Land } \\
\text { Cover } 1 \mathrm{~km}\end{array}$ & $\begin{array}{l}\text { Urban and built- } \\
\text { up areas }\end{array}$ & $\sim 1 \mathrm{~km}$ & $\begin{array}{l}\text { MODIS, Landsat-based map } \\
\text { for training and assessment } \\
\text { and LITES }\end{array}$ & $\begin{array}{l}\sim 90 \% \\
(0.67)\end{array}$ \\
\hline 8 & $\begin{array}{l}\text { GRUMP (CIESIN, } \\
\text { 2004) }\end{array}$ & $\begin{array}{l}\text { Global Rural-Urban } \\
\text { Mapping Project }\end{array}$ & Urban extent & $\sim 1 \mathrm{~km}$ & $\begin{array}{l}\text { VMAP, census data, } \\
\text { Nighttime lights maps }\end{array}$ & $\begin{array}{l}\sim 75 \% \\
(0.75)\end{array}$ \\
\hline 9 & $\begin{array}{l}\text { Lights } \\
\text { (Elvidge et al., } \\
\text { 2001; Imhoff et al., } \\
\text { 1997) }\end{array}$ & Nighttime Lights v2 & Nighttime Lights & $\sim 1 \mathrm{~km}$ & DMSP-OLS dataset & - \\
\hline 10 & $\begin{array}{l}\text { LandScan } \\
\text { (Bhaduri et al., } \\
\text { 2002) }\end{array}$ & LandScan 2005 & Population & $\sim 1 \mathrm{~km}$ & $\begin{array}{l}\text { Geocover maps, VMAP0, } \\
\text { MODIS 1-km, Landsat, census } \\
\text { data, high-resolution imagery }\end{array}$ & - \\
\hline
\end{tabular}

Mean-Squared-Error (RMSE) of $3.205 \mathrm{~km}^{2}(\sim 0.2 \%$ in terms of the SMOS pixel coverage).

The NAFE'06 was conducted over three focus areas of the Murrumbidgee River catchment (Kyeamba, Yanco, and Yenda) in southeast Australia, from $29^{\text {th }}$ Oct. to $20^{\text {th }}$ Nov. 2006. During the campaign, airborne multi-angular brightness temperatures in dual-polarization (horizontal and vertical) were collected at low $(\sim 1$ $\mathrm{km})$, medium $(\sim 500 \mathrm{~m})$, high $(\sim 125 \mathrm{~m})$, and very high $(\sim 62.5 \mathrm{~m})$ resolutions using the Polarimetric L-band Multi-beam Radiometer (PLMR) at incidence angles of $7^{\circ}, 21.5^{\circ}$, and $38.5^{\circ}$. In addition, time series of pointbased soil temperature, soil moisture, rainfall, and soil suction were acquired via the OzNet monitoring stations during the campaign (www.oznet.org.au). In the present study, only PLMR data collected throughout the Kyeamba study area at $\sim 1 \mathrm{~km}$ resolution were used. This particular study area is a $50 \mathrm{~km} \times 40 \mathrm{~km}$ rectangle covered dominantly by silty loam soils and with mostly pasture land. However, the city of Wagga Wagga is located in the north-western corner covering an area of 4,825 $\mathrm{km}^{2}$, and with population of 62,904 in 2009 (Australian Bureau of Statistics, 2010). During the campaign, a mean surface $(2.5 \mathrm{~cm})$ soil temperature of $20.5{ }^{\circ} \mathrm{C}$, a mean deep $(15 \mathrm{~cm})$ soil temperature of $20.4{ }^{\circ} \mathrm{C}$, a mean surface (top $5 \mathrm{~cm}$ ) soil moisture of $0.066 \mathrm{~m}^{3} / \mathrm{m}^{3}$, and a cumulated rainfall of $40.4 \mathrm{~mm}$ were measured via OzNet sites within the Kyeamba study area. The temporal variation of the brightness temperature observations during flights was corrected to mean flight time by using monitoring station data. The corrected brightness temperature was then normalized to the incidence angle of $38.5^{\circ}$. Table 2 summarizes main features of processed brightness temperature and observed soil moisture and temperature for each of the sampling flights. The contribution of Lake Albert in the south of Wagga Wagga was removed from this study.

The LUNSW is a polygon formatted land use map of New South Wales. Land use type classification was undertaken based on a combination of satellite imagery, aerial photography, existing datasets, local

Table 2. Summary of main data collected during low $(\sim 1 \mathrm{~km})$ resolution flight over Kyeamba study area.

\begin{tabular}{|c|c|c|c|c|c|}
\hline Sampling Date & $\begin{array}{c}\text { Mean flight } \\
\text { time }\end{array}$ & $\begin{array}{c}\text { H polarized } \\
\text { brightness } \\
\text { temperature }(\mathrm{K}) \\
\mu(\sigma)\end{array}$ & $\begin{array}{c}\text { V polarized } \\
\text { brightness } \\
\text { temperature }(\mathrm{K}) \\
\mu(\sigma)\end{array}$ & $\begin{array}{c}\text { Top 5cm soil } \\
\text { moisture } \\
\left(\mathrm{m}^{3} / \mathrm{m}^{3}\right)\end{array}$ & $\begin{array}{c}\text { Estimated effective } \\
\text { soil temperature } \\
(\mathrm{K})\end{array}$ \\
\hline $30^{\text {th }}$,Oct. 2006 & $12: 00$ & $269.3(5.3)$ & $283.2(4.9)$ & 0.03 & 300.4 \\
\hline $06^{\text {th }}$, Nov. 2006 & $10: 00$ & $257.7(7.1)$ & $276.3(4.7)$ & 0.07 & 0.08 \\
\hline $20^{\text {th }}$,Nov. 2006 & $9: 20$ & $254.91(8.9)$ & $273.8(5.3)$ & 298.8 & \\
\hline
\end{tabular}




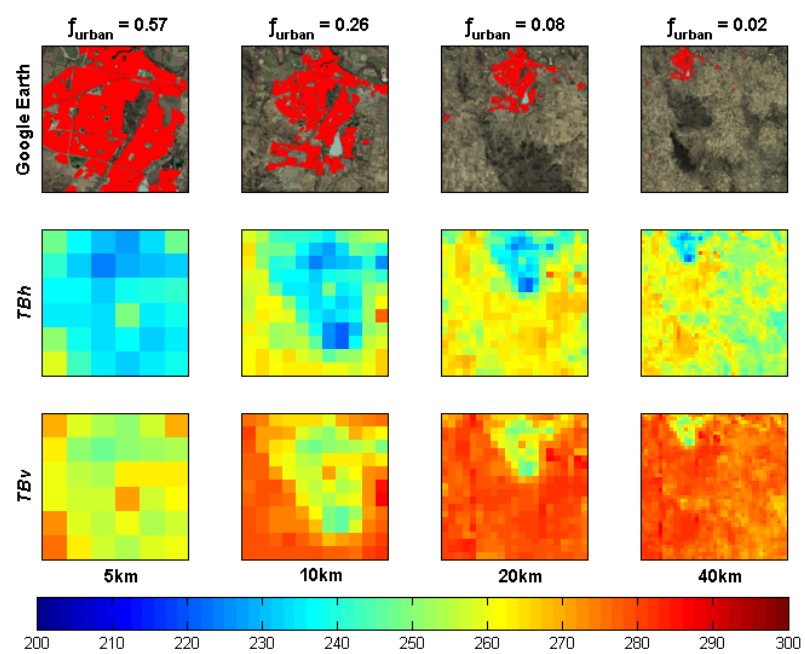

Figure 3. Google Earth images and dual-polarized brightness temperature ( $T B_{h}$ and $\left.T B_{v}\right)$ maps at multiple scales over the city of Wagga Wagga on 06 Nov. 2006. Red polygons in the Google Earth images indicate the urban areas identified based on LUNSW. knowledge and field validation. Generally, the LUNSW has a positional accuracy of $50 \mathrm{~m}$, and an attribute accuracy of $92-99 \%$ (New South Wales Department of Environment \& Climate Change, 2007). In this study, only the urbanrelated class was considered, and so the LUNSW was re-categorized into a binary map (dense urban/natural). The dense urban category includes industrial/commercial and residential subclasses from the urban class, as well as the airport subclass from the transport class. The remaining subclasses in urban and transport classes were discarded as most of them are dominated by natural land surface which should have similar radiometric characteristics to the surrounding natural land surfaces.

The MODIS 500-m mask was developed from one year of 8-day MODIS 500-m Nadir BRDFAdjusted Reflectance (NBAR) observations, by applying a supervised classification model which was trained using $30-\mathrm{m}$ resolution Landsat-based maps (Angel et al., 2005; Schneider and Woodcock, 2008). It defines urban areas as pixels with more than $50 \%$ non-vegetated, human-constructed elements with a size in excess of $1 \mathrm{~km}^{2}$ in MODIS 500-m (Schneider et al., 2009).

\section{RESULT AND DISCUSSION}

In order to obtain the curve of urban induced brightness temperature uncertainties $\left(\Delta T B_{\text {urban }}\right)$ versus urban fraction $\left(f_{\text {urban }}\right)$, brightness temperature observations over mixed scenes with a range of urban fractions were required. Since the urban fraction coverage of the $40 \mathrm{~km}$ pixel over Wagga Wagga is only $2 \%$, variation in the fraction coverage was achieved by sub setting the original $40 \mathrm{~km}$ footprint. Consequently, the scene extent was set to range from $5 \mathrm{~km}$ to $40 \mathrm{~km}$, yielding an urban fraction range of up to $\sim 25 \%$. Figure 3 shows dualpolarized brightness temperature maps at four scales $(5,10,20$, and $40 \mathrm{~km})$ observed on $6^{\text {th }}$ Nov. 2006. The Google Earth images in the first row of Figure 3 illustrate the land surface composition at the different spatial extents, with the boundary of the dense urban area identified using LUNSW. For each pixel coverage, the urban fraction $\left(f_{\text {urban }}\right)$, mean brightness temperatures of non-urban component in the pixel $\left(T B_{\text {non-urban }}\right)$, and the mean brightness temperature of the entire area $\left(T B_{\text {all }}\right)$ were calculated in order to establish the relationship between urban induced brightness temperature uncertainties $\left(\Delta T B_{\text {urban }}=T B_{\text {non-urban }}\right.$ $\left.T B_{\text {all }}\right)$ and urban fraction.

The brightness temperatures collected in the three sampling days display similar patterns to those shown in Figure 3 for $6^{\text {th }}$ Nov. 2006. In Figure 4, the relationship between urban induced brightness temperature uncertainties $\left(\Delta T B_{\text {urban }}\right)$ is plotted against urban fraction $\left(f_{\text {urban }}\right)$ together with a line presenting the $4 \mathrm{~K}$ benchmark. As expected, $\Delta T B_{\text {urban }}$ is proportional to $f_{\text {urban, }}$, and a value of 9 $16 \%$ can be set to both polarizations as the urban fraction threshold for achieving a $4 \mathrm{~K}$ target, although urban fraction threshold for horizontal polarization should be $\sim 0.02$ higher than that of vertical polarization. It was also be found that dualpolarized brightness temperatures of urban areas were $\sim 35 \mathrm{~K}$ lower than those of surrounding dry natural surfaces under the conditions of this

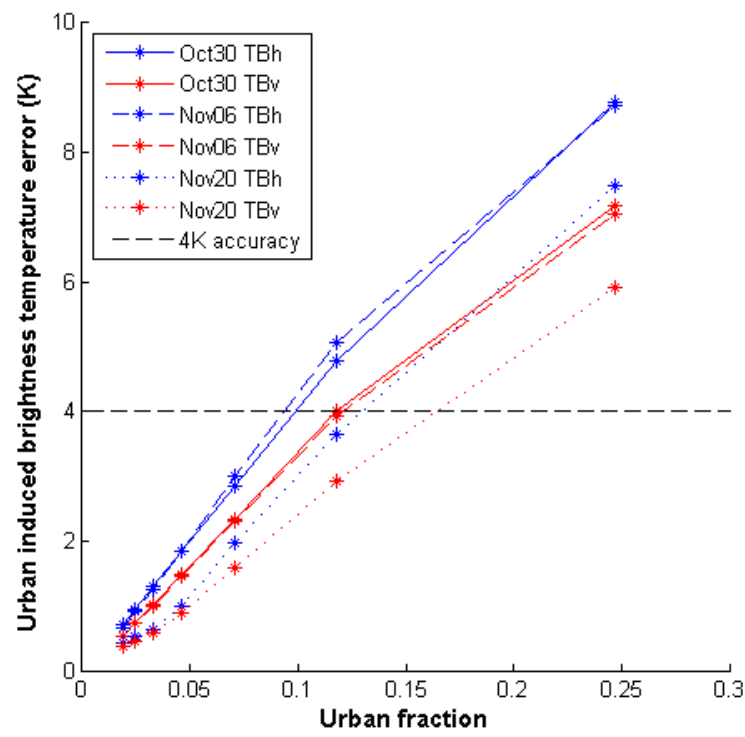

Figure 4. The relationship between brightness temperature error and urban fraction from NAFE'06 data. 
experimental data set, which implies that urban behaves like a target with a higher dielectric constant and/or a lower surface roughness than dry natural soil surface.

The urban fraction of SMOS pixels across Australia was calculated using MODIS 500-m, and the cumulated numbers of pixels were plotted against urban fraction in Figure 5. It shows that using the urban fraction threshold of $9 \%$ derived for the conditions over Wagga Wagga during NAFE'06, there are only a total of 116 pixels out of the 43,323 SMOS pixels covering Australia that have potential non-negligible urban impacts.

\section{CONCLUSIONS}

This study identified the SMOS pixels with potential urban induced uncertainties over Australia exceeding the average observational error of SMOS of $4 \mathrm{~K}$ (under warm dry summer conditions), by comparing the urban fraction of SMOS pixels with an urban fraction threshold.

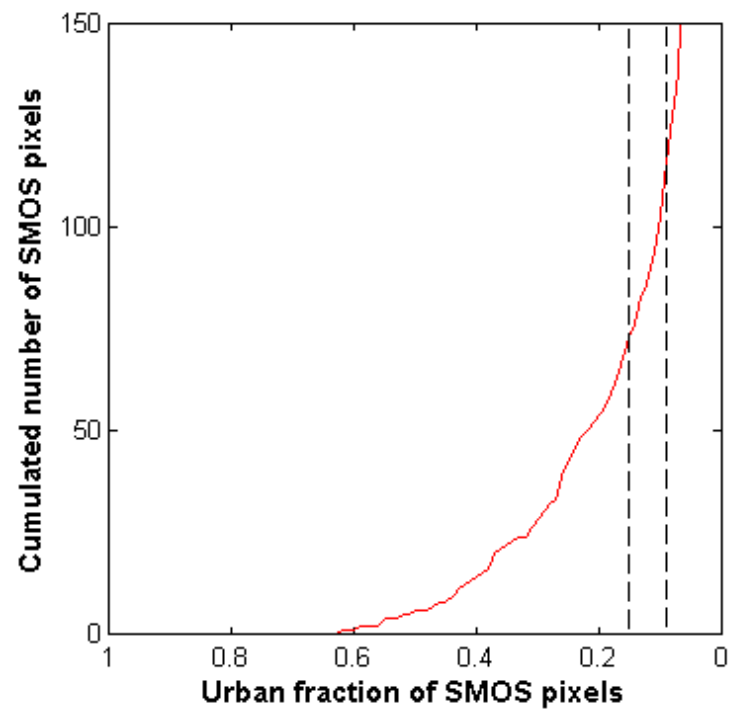

Figure 5. The relationship between cumulated number of SMOS pixels in Australia according to their urban fraction (red line), and the urban threshold of $9-16 \%$ (black dashed lines) The urban induced uncertainty is defined as the contribution of urban areas to overall brightness temperature observations which potentially results in significant soil moisture retrieval error if the contribution is neglected by radiometric models. The urban fraction threshold of $9-16 \%$ for a $4 \mathrm{~K}$ error benchmark was obtained from brightness temperature observations in NAFE'06 over the Kyeamba study area, which includes the city of Wagga Wagga, using the LUNSW dataset to identify urban areas and calculate urban fraction. However, a major assumption of this study is that the microwave behaviour of the studied city is representative to that of all Australian cities. This urban fraction threshold was then applied to SMOS pixels across Australia based on urban fraction calculated using MODIS $500-\mathrm{m}$. It was found that only $\sim 0.2 \%$ (116 out of 43,323 ) of SMOS pixels over Australia are expected to have potential brightness temperature uncertainty of more than $4 \mathrm{~K}$ under warm dry conditions if the presence of urban area is ignored.

This study only presents urban fraction threshold derived from real brightness temperature observations over one medium sized Australian city during dry mid-morning conditions of late spring. Compared with previews studies (Kerr, et al., 2010 b; Loew, 2008), a similar urban fraction threshold was found of $4 \mathrm{~K}$ error benchmark, however brightness temperature of urban area was observed lower than that of soil. Further studies on the dependence of urban induced uncertainty as a function of city size, type, location, time of day, season and/or soil moisture and vegetation water content conditions are needed to confirm the generalisation of these results throughout Australia and indeed the world.

\section{ACKNOWLEDGMENTS}

This project is funded by an Australian Research Council Discovery Project (DP0879212). The authors wish to thank Professor Annemarie Schneider from University of Wisconsin-Madison for providing access to MODIS Urban Land Cover $500 \mathrm{~m}$. The authors would also like to thank Dr. Narendra Das and Dr. Steven Chan from California Institute of Technology for their constructive idea to this study.

\section{REFERENCES}

Angel S, Sheppard S and Civco D 2005 The dynamics of global urban expansion World Bank Report (Washington, DC: The World Bank)

Arino, O., Gross, D., Ranera, F., Bourg, L., Leroy, M., Bicheron, P., et al. (2007). GlobCover: ESA service for global land cover from MERIS. Proceedings of the international geoscience and remote sensing symposium, 23-28 July 2007, Barcelona, Spain, doi: 10.1109/IGARSS.2007. 4423328.

Australian Bureau of Statistics, (2010). National Regional Profile: Wagga Wagga (C) (Local Government Area), www.abs.gov.au/AUSSTATS/abs@nrp.nsf/Latestproducts/LGA17750Main\%20Features120052009? opendocument\&tabname $=$ Summary \&prodno $=$ LGA17750\&issue $=2005-2009 \&$ num $=\& v i e w=, \quad$ last accessed on 17 July 2011. 
Ye et al., The effect of urban cover fraction on the retrieval of surface soil moisture at L-band

Bartholome, E., and Belward, A. S. (2005). GLC2000: A new approach to global land cover mapping from Earth observation data. International Journal of Remote Sensing, 26, 1959-1977.

Bhaduri, B., Bright, E., Coleman, P., \& Dobson, J. (2002). LandScan: Locating people is what matters. Geoinfomatics, 5, 34-37.

CIESIN, Center for International Earth Science Information Network. (2004). Global Rural-Urban Mapping Project (GRUMP), Alpha Version: Urban Extents. http://sedac.ciesin.columbia.edu/gpw last accessed on 18 July 2011.

Danko, D. M. (1992). The digital chart of the world project. Photogrammetric Engineering and Remote Sensing, 58, 1125-1128.

Dirmeyer, P.A. (2000), Using a global soil wetness dataset to improve seasonal climate simulation. Journal of Climate, 13, 2900-2922.

Elvidge, C., Imhoff, M. L., Baugh, K. E., Hobson, V. R., Nelson, I., Safran, J., et al. (2001). Nighttime lights of the world: 1994-95. ISPRS Journal of Photogrammetry and Remote Sensing, 56, 81-99.

Elvidge, C., Tuttle, B. T., Sutton, P. C., Baugh,K. E.,Howard,A. T.,Milesi, C., et al. (2007). Global distribution and density of constructed impervious surfaces. Sensors, 7, 1962-1979.

ESA, European Space Agency (2008). GlobCover products description and validation report.ftp://uranus.esrin.esa.int/pub/globcover_v2/global/GLOBCOVER_Products_Description_Validatio $\mathrm{n}$ Report I2.1.pdf, last accessed on 18 July 2011.

Imhoff, M. L., Lawrence, W., Stutzer, D., \& Elvidge, C. (1997). A technique for using composite DMSP/OLS “city lights" satellite data to map urban areas. Remote Sensing of Environment, 61, 361-370.

Goldewijk, K. (2001). Estimating global land use change over the past 300 years: The HYDE database. Global Biogeochemical Cycles, 15, 417-434.

Goldewijk, K. (2005). Three centuries of global population growth: A spatially referenced population density database for 1700-2000. Population and Environment, 26, 343-367.

Kerr, Y.H., Waldteufel, P., Wigneron, J.-P., Delwart, S., Cabot, F., Boutin, J., Escorihuela, M.-J., Font, J., Reul, N., Gruhier, C., Juglea, S.E., Drinkwater, M.R., Hahne, A., Martín-Neira, M., Mecklenburg, S., (2010 a). The SMOS Mission: New Tool for Monitoring Key Elements of the GlobalWater Cycle. Proceedings of the IEEE, 98 (5), 666 - 687.

Kerr, Y.H. and Waldteufel, P., (2003). Note on SMOS calibration and validation. Cesbio Technical Report, www.cesbio.ups-tlse.fr/data all/SMOS-doc/SO2b.pdf, last accessed on 17 July 2011.

Kerr, Y.H., Waldteufel, P., Richaume, P., Davenport, I., Ferrazzoli, P., and Wigneron, J.-P. (2010 b), SMOS level 2 processor soil moisture algorithm theoretical basis document (ATBD). CESBIO, Toulouse, France. $S M-E S L$ (CBSA), SO-TN-ARR-L2PP-0037, ESA Internal report, V3.4. [Online]. Available: http://www.cesbio.ups-tlse.fr/us/indexsmos.html.

Koster, R.D. and Suarez, M.J. (2001), Soil moisture memory in climate models. Journal of Hydrometeorology, 2, 558-570.

Loew, A. (2008). Impact of surface heterogeneity on surface soil moisture retrievals from passive microwave data at the regional scale: The Upper Danube case. Remote Sensing of Environment, 112 (2008), 231-248.

Lomas, T. (2003), Create Thiessen Polygons 3.0. http://arcscripts.esri.com/details.asp?dbid=11958, last accessed on 25 July 2011.

Merlin, O., Walker, J. P., Kalma, J. D., Kim, E., Hacker, J., Panciera, R., Young, R., Summerell, G., Hornbuckle, J., Hafeez, M., and Jackson, T., 2008. The NAFE'06 data set: Towards Soil Moisture Retrieval at Intermediate Resolution. Advances in Water Resources, 31 (2008), 1444-1455.

New South Wales Department of Environment \& Climate Change, (2007), Metadata statement: Land Use mapping - New South Wales, Metadata statement, www.canri.nsw.gov.au/download/NSW_Land_Use_Mapping_metadata.pdf, last accessed on 17 July 2011.

Schneider, A., Friedl, M. A., Mciver, D. K., \& Woodcock, C. E. (2003). Mapping urban areas by fusing multiple sources of coarse resolution remotely sensed data. Photogrammetric Engineering and Remote Sensing, 69, 1377-1386.

Schneider A and Woodcock C 2008 Compact, dispersed, fragmented, extensive? A comparison of urban expansion in twenty-five global cities using remotely sensed, data pattern metrics and census information Urban Stud. 45 659-92

Schneider, A., Friedl, M. A., and Potere, D. (2009). A new map of global urban extent from MODIS satellite data.Environmental Research Letters, 4 article 044003

Schneider, A., Friedl, M. A., and Potere, D. (2010). Mapping global urban areas using MODIS 500-m data: New methods and datasets based on 'urban ecoregions'. Remote Sensing of Environment, 114 (2010), 1733-1746. 